\title{
PENGARUH KEMAMPUAN MANAJERIAL KEPALA SEKOLAH DAN KOMITE SEKOLAH TERHADAP BUDAYA ORGANISASI DAN EFEKTIFITAS PENYELENGGARAAN SEKOLAH
}

\author{
Masrukhin \\ IAIN Kudus Indonesia \\ masrukhinkhin@gmail.com
}

\begin{abstract}
THE EFFECT OF MANAGERIAL CAPABILITIES OF HEADMASTER AND SCHOOL COMMITTEE ON ORGANIZATIONAL CULTURE AND SCHOOL EFFECTIVENESS. This study aims to find, describe, predict and verify the theory. This survey research used quantitative approach. Sampling technique was Cluster Sampling or Sampling Area at High School as many as 100 schools from 105 schools. Data collected using questionnaire. This research consists of two variables, namely exogenous latent variable, the Managerial ability of headmaster $\left(\xi_{1}\right)$ and School Committee $\left(\xi_{2}\right)$ and endogenous latent variables are School Organization Culture $\left(\eta_{1}\right)$ and School Effectiveness $\left(\eta_{2}\right)$. Data analysis techniques used Structural Equation Modelling (SEM). Based on the result of descriptive statistical analysis, both exogenous and endogenous latent variables are in good category. Theoretical model expressed fit. The magnitude of the effect of each exogenous variable on the endogenous variable and the contribution of the construct indicator are: (1) School effectiveness is not determined directly by the Managerial ability of headmaster, (2) The school organization culture is determined by the managerial ability of headmaster, (3) School effectiveness is not determined directly by the principal's managerial skills through the school's organizational culture
\end{abstract}


(4) School effectiveness is not defined by the school committee, (5) School organization culture is not determined by the school committee, (6) School effectiveness is not determined directly by the school committee through school organization culture, (7) School effectiveness is determined directly by the school organization culture. The contribution of each indicator to the construct is: (1) Managerial ability of headmaster variable is the $M_{3}$ (Technical Skill) dimension, with a value of $R^{2}$ of 0.76 or $76 \%$., (2) School Committee variable is the $K_{3}$ dimension (Advisory Agency), with a $R^{2}$ value of 0.92 or $92 \%$, (3) School Organization Cultural variable is the dimension of $B_{4}$ (Philosphy), with an estimated value of $0.67,(4)$ School Effectiveness variable is the dimension $E_{4}$ (Standards of Teachers) with an estimated value of 0.99 .

Keywords: Managerial ability of headmaster, school committees, school organization culture, school effectiveness, Structural Equation Modelling (SEM).

\begin{abstract}
Abstrak
Penelitian ini bertujuan untuk mengetahui, mendeskripsikan, memprediksi dan verifikasi teori. Jenis penelitian survey dengan pendekatan kuantitatif. Teknik pengambilan sampel menggunakan Cluster Sampling atau Area Sampling pada Sekolah Menengah Atas sebanyak 100 sekolah dari 105 sekolah. Pengumpulan data dengan menggunakan angket. Penelitian ini terdiri dari dua variabel yaitu variabel laten eksogen, Kemampuan Manajerial Kepala Madrasah $\left(\xi_{1}\right)$ dan Komite Madrasah $\left(\xi_{2}\right)$ dan variabel laten endogen, yaitu Budaya Organisasi Madrasah $\left(\eta_{1}\right)$ dan Keefektifan Madrasah $(\eta$ $\left.{ }_{2}\right)$. Teknik analisis data menggunakan Structural Equation Modeling (SEM). Berdasarkan hasil analisis statistik deskriptif baik variabel laten eksogen dan endogen, nilai rata-rata termasuk dalam kategori baik. Model teoritis dinyatakan fit. Besarnya pengaruh setiap variabel eksogen terhadap variabel endogen dan sumbangan indikator konstruk yaitu: (1) Keefektifan sekolah tidak ditentukan secara langsung oleh kemampuan manajerial kepala sekolah, (2) Budaya organisasi sekolah ditentukan oleh kemampuan manajerial kepala sekolah, (3) Keefektifan sekolah ditentukan tidak secara langsung oleh kemampuan manajerial kepala sekolah melalui budaya organisasi sekolah, (4) Keefektifan sekolah tidak diditentukan oleh komite sekolah, (5) Budaya Organisasi sekolah tidak ditentukan oleh komite sekolah, (6) Keefektifan sekolah tidak ditentukan secara langsung oleh komite sekolah melalui budaya organisasi sekolah, (7) Keefektifan sekolah ditentukan secara langsung
\end{abstract}


oleh budaya organisasi sekolah. Sumbangan dari setiap indikator terhadap konstruk yaitu: (1) variabel Kemampuan Manajerial Kepala Sekolah adalah dimensi M3 (Technical Skill), dengan nilai $\mathrm{R}^{2}$ sebesar 0,76 atau 76\%., (2) variabel Komite Sekolah adalah dimensi K3 (Advisory Agency), dengan nilai $\mathrm{R}^{2}$ sebesar 0,92 atau 92\%, (3) variabel Budaya Organisasi Sekolah adalah dimensi $\mathrm{B}_{4}$ (Philosphy), dengan nilai estimasi sebesar 0,67, (4) variabel Keefektifan Sekolah adalah dimensi $\mathrm{E}_{4}$ (Standar Tenaga Pendidik), dengan nilai estimasi sebesar 0.99 .

Kata Kunci: Kemampuan manajemen kepala sekolah, komite sekolah, budaya organisasi sekolah, keefektifan sekolah, Structural Equation Modeling (SEM).

\section{A. Pendahuluan}

Modal utama pembangunan nasional adalah sumberdaya manusia yang terdidik. Semakin banyak orang yang berpendidikan, maka semakin mudah bagi suatu negara untuk membangun bangsanya yang berpijak dari kemandirian bangsa. Pendidikan yang berorientasi pada penguasaan keterampilan, ilmu pengetahuan, dan teknologi dan didukung dengan peningkatan dana pendidikan akan memudahkan pemerintah dalam menggerakkan pembangunan nasional. Keluaran pendidikan yang dapat digunakan untuk mendorong partisipasi masyarakat dalam pembangunan nasional adalah keluaran pendidikan yang berkualitas. Disamping itu juga akses pendidikan bagi semua warga negara dengan prinsip pemerataan pendidikan untuk semua (Education For All, EFA) dapat dirasakan oleh semua warga masyarakat baik kaya maupun miskin, masyarakat pedalaman (daerah terpencil) maupun perkotaan (Ustama, 2009, p. 4).

Berbagai macam upaya telah dilakukan untuk meningkatkan sumber daya manusia melalui pendidikan yang efektif belum mencapai hasil yang optimal. Problematika rendahnya mutu SDM ini dapat dilihat dari beberapa indikator makro antara lain dari laporan The Global Competitiveness Report 2008-2009 dari World Economic Forum (dalam Martin, dkk., 2008), yang menempatkan Indonesia pada peringkat 55 dari 134 negara dalam hal pencapaian Competitiveness Index (CI). Hasil penelitian United Nations for Development Programme di dalam Human Development 
Report 2007/2008 yang menempatkan Indonesia pada posisi ke107 dari 155 negara dalam pencapaian Human Development Index (HDI) (Tjalla, 2010, p. 2).

Konsekuensi logis dari rendahnya mutu sumber daya manusia, maka diperlukan penelitian tentang keefektifan sekolah dengan mempertimbangkan variabel-variabel seperti kemampuan manajerial kepala sekolah dan komite sekolah diharapkan mampu membangun budaya organisasi sekolah. Hal ini berarti, keefektifan sekolah yang berorientasi pada peningkatan mutu pendidikan dasar dan menengah tidak dapat lepas dari pengaruh variabelvariabel tersebut, baik secara langsung maupun tidak langsung.

Berdasarkan hal tersebut di atas, maka peneliti memfokuskan penelitian ini mengenai Pengaruh Kemampuan Manajerial Kepala Sekolah dan Komite Sekolah Terhadap Budaya Organisasi Sekolah dan Dampaknya Pada Keefektifan Sekolah (Survey Pada Sekolah Menengah Atas (SMA) se-Wilayah Eks Karesidenan Pati). Rumusan permasalahan dari kajian ini diantaranya: (1). Apakah kemampuan manajerial kepala sekolah berpengaruh langsung terhadap keefektifan sekolah?, (2). Apakah kemampuan manajerial kepala sekolah berpengaruh langsung terhadap budaya organisasi sekolah?, (3) Apakah kemampuan manajerial kepala sekolah berpengaruh tidak langsung melalui budaya organisasi sekolah terhadap keefektifan sekolah?, (4). Apakah komite sekolah berpengaruh langsung terhadap keefektifan sekolah?, (5). Apakah komite sekolah berpengaruh langsung terhadap budaya organisasi sekolah?, (6). Apakah komite sekolah berpengaruh tidak langsung melalui budaya organisasi sekolah terhadap keefektifan sekolah?, (7). Apakah budaya organisasi sekolah berpengaruh langsung terhadap keefektifan sekolah?

\section{Paradigma Penelitian}

Ketiga variabel laten eksogen yakni kemampuan manajerial kepala sekolah dan komite sekolah serta budaya organisasi sekolah berpengaruh positif terhadap keefektifan sekolah. Oleh karena itu, dugaan adanya pengaruh positif langsung ataupun tidak langsung dapat diuraikan pada gambar 1 di bawah ini. 


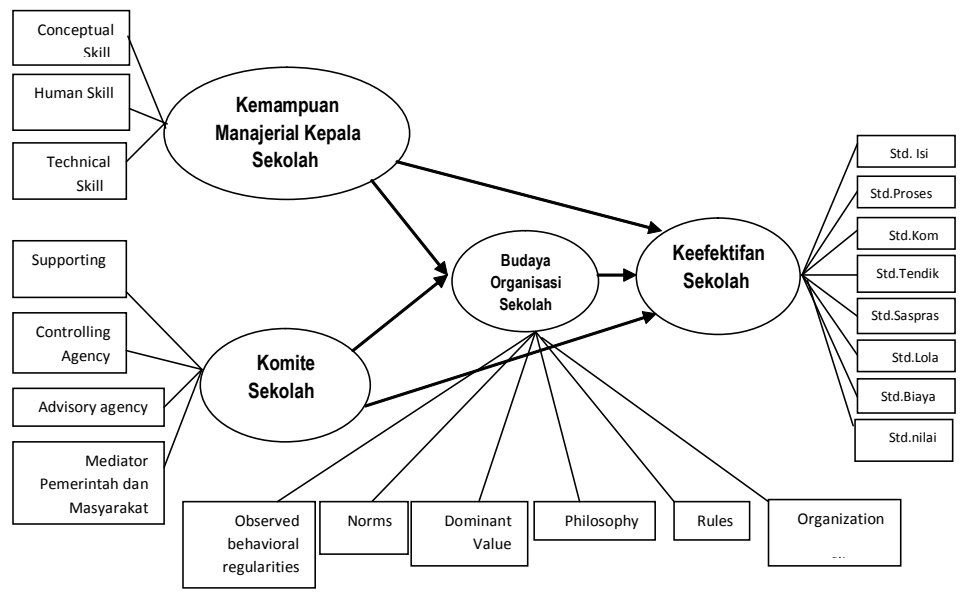

Gambar 1. Kerangka Pemikiran

\section{Hipotesis Penelitian}

Berdasarkan kajian teori yang telah disebutkan sebelumnya, serta kerangka alur berpikir di atas dapat dikemukakan beberapa hipothesis alternative $\left(\mathrm{H}_{\mathrm{a}} / \mathrm{H}_{1}\right)$ penelitian sebagai berikut: $(1)$. Kemampuan manajerial kepala sekolah berpengaruh langsung terhadap keefektifan sekolah, (2). kemampuan manajerial kepala sekolah berpengaruh langsung terhadap budaya organisasi sekolah, (3). Kemampuan manajerial kepala sekolah berpengaruh tidak langsung melalui budaya organisasi sekolah terhadap keefektifan sekolah, (4). Komite sekolah berpengaruh langsung terhadap keefektifan sekolah, (5). Komite sekolah berpengaruh langsung terhadap budaya organisasi sekolah, (6). Komite sekolah berpengaruh tidak langsung melalui budaya organisasi sekolah terhadap keefektifan sekolah, (7). Budaya organisasi sekolah berpengaruh langsung terhadap keefektifan sekolah.

\section{Desain Penelitian}

Penelitian ini menggunakan metode Survai. Metode Survai adalah upaya mengumpulkan informasi dari responden yang merupakan contoh dengan menggunakan kuesioner yang terstruktur. Pendekatan yang akan digunakan dalam penelitian ini adalah pendekatan kuantitatif dengan jenis penelitian korelasional 
yakni jenis penelitian yang bertujuan untuk mengetahui ada tidaknya hubungan antar beberapa variabel (Suharsimi Arikunto, 1990, p. 326).

\section{Populasi dan Sampel}

Data primer yang akan dikumpulkan di beberapa sekolah yang menjadi sampel dengan Cluster Sampling atau Area Sampling yaitu teknik sampling daerah yang digunakan untuk menentukan bila objek yang diteliti sangat luas (Sugiyono, 2002, p. 121). SMA sebagai unit analisis dalam penelitian ini, diambil dengan menggunakan kaidah yang dikembangkan oleh Isaac dan Michael dengan toleransi kesalahan 10 \% (Sugiyono, 2002, p. 126) ditentukan jumlah sampel sebanyak 100 sekolah dari populasi 105 . Kemudian sampel tersebut diambil di setiap daerah secara proporsional.

\section{Identifikasi Variabel}

Variabel utama dalam penelitian ini adalah keefektifan sekolah yang diukur dari Standar Nasional Pendidikan di sekolahsekolah di se-Wilayah Eks Karesidenan Pati. Sedangkan variabel lainnya terdiri dari Kemampuan Manajerial Kepala Sekolah, Komite Sekolah dan Budaya Organisasi Sekolah akan ditelusuri di setiap sampel. Selanjutnya variabel ini dikelompokkan menjadi dua yakni variabel laten eksogen dan variabel laten endogen. Variabel laten eksogen adalah variabel yang tidak diprediksi oleh variabel lain dalam model. Variabel laten eksogen dalam penelitian ini adalah Kemampuan Manajerial Kepala Sekolah $\left(\xi_{1}\right)$ dan Komite Sekolah $\left(\xi_{2}\right)$. Kemudian Variabel laten endogen adalah variabel yang dipengaruhi oleh variabel eksogen atau diprediksi oleh satu atau beberapa variabel lain dalam model. Variabel laten endogen pada penelitian ditentukan sebagai Budaya Organisasi Sekolah $\left(\eta_{1}\right)$ dan Keefektifan Sekolah $\left(\eta_{2}\right)$.

\section{Definisi Operasional Variabel}

Variabel Kemampuan Manajerial Kepala Sekolah $\left(\xi_{1}\right)$ akan dimanifestasikan oleh conceptual skill, human skill dan technical skill yang dapat dirumuskan sebagai $\left(M_{1}, M_{2}\right.$ dan $\left.M_{3}\right)$. Komite 
Sekolah $\left(\xi_{2}\right)$. adalah supporting agency, advisory agency, controlling dan mediator pemerintah dan masyarakat dapat dirumuskan sebagai $\left(\mathrm{K}_{1}, \mathrm{~K}_{2}, \mathrm{~K}_{3}\right.$ dan $\left.\mathrm{K}_{4}\right)$. Variabel Budaya Organisasi Sekolah $\left(\eta_{1}\right)$ akan diungkap melalui (1) obeserved behavioral regularities; (2) norms; (3) dominant value. (4) philosophy; (5) rules dan (6) organization climate yang dapat dirumuskan sebagai $\left(\mathrm{B}_{1}, \mathrm{~B}_{2}, \mathrm{~B}_{3}, \mathrm{~B}_{4}\right.$ $\mathrm{B}_{5}$ dan $\left.\mathrm{B}_{6}\right)$. Variabel Keefektifan Sekolah $\left(\eta_{2}\right)$ akan dikaji sejauh mana tingkat capaian sekolah yang bersangkutan dilihat dari: 1 ) standar isi; 2) standar proses; 3 ) standar kompetensi kelulusan; 4) standar pendidikan dan tenaga kependididkan; 5) standar sarana dan prasarana; 6) standar pengelolaan; 7) standar pembiayaan; 8) standar penilaian pendidikan, dapat dirumuskan sebagai $\left(\mathrm{E}_{1}, \mathrm{E}_{2}\right.$, $\mathrm{E}_{3,} \mathrm{E}_{4}, \mathrm{E}_{5,}, \mathrm{E}_{6}, \mathrm{E}_{7}$ dan $\left.\mathrm{E}_{8}\right)$.

\section{Validitas dan Reliabilitas Instrumen Penelitian}

Data penelitian ini dikumpulkan dengan menggunakan angket dibuat berdasarkan rating scale. Khusus untuk angket peneliti akan menggunakan skala sikap dari rating scale dan semantic differensial dengan skoring $(S S=5, S=4, R=3, T S=2, S T S=1)$ dan melakukan serangkaian uji coba validitas dan reliabilitas angket dengan mengambil sampel sebanyak 30 responden. Adapun hasil uji validitas dinyatakan valid semua dan reliabel.

\section{Instrumen dan Teknik Pengumpulan Data}

Data kemampuan manajerial kepala sekolah, komite sekolah, budaya organisasi sekolah dan keefektifan sekolah merupakan data primer yang diperoleh dari angket yang diberikan kepada sekolah dan merupakan persepsi yang diberikan oleh kepala SMA, Guru dan Komite Sekolah terhadap permasalahan yang dimaksud. Selanjutnya keseluruhan data dan informasi ini merupakan persepsi sumber informasi yaitu kepala sekolah, guru, komite sekolah akan ditelusuri dengan menggunakan kuesioner skala sikap model rating scale dan semantic differensial.

\section{Teknik Pengolahan dan Analisis Data}

Metode analisis yang digunakan dalam penelitian ini adalah model persamaan simultan yakni persamaan struktural 
atau structural equation model (SEM). SEM merupakan suatu pemodelan multivariat untuk menganalisis hubungan-hubungan persamaan struktural (linear structural relationships), atau lebih populer disebut dengan LISREL. Pemodelan persamaan struktural terdiri atas dua model, yaitu model struktural dan model pengukuran (Wijanto, 2008, p. 12).

\section{B. Pembahasan}

\section{Kemampuan Manajerial Kepala Sekolah}

Kemampuan manajerial kepala sekolah adalah seperangkat keterampilan teknis dalam melaksanakan tugas sebagai manajer sekolah untuk mendayagunakan segala sumber yang tersedia untuk mencapai tujuan sekolah secara efektif dan efisien. Dalam menjalankan kinerja manajerialnya, kepala sekolah memiliki tiga jenis keterampilan, yaitu technical, human, dan conceptual. Ketiga keterampilan manajerial tersebut berbeda-beda sesuai dengan tingkat kedudukan manajer dalam organisasi (Engkay, Guru, Subang, Trubus, \& Karang Anyar, 2010, p. 78).

Kepemimpinan dipandang sebagai upaya memberikan sebuah kultur pengajaran dan pembelajaran yang kondusif. Kepemimpinan yang mampu meningkat mutu pendidikan hendaknya :

a. Memberikan kesempatan kepada anggota untuk berpartisipasi dalam proses perubahan guna merefleksikan praktek dan mengembangkan pemahaman personal tentang sifat dan implikasi perubahan terhadap diri mereka;

b. Mendorong mereka yang terlibat dalam implementasi perbaikan untuk membentuk kelompok-kelompok sosial dan membangun tradisi saling mendukung selama proses perubahan;

c. Membuka peluang feedback positif bagi semua pihak yang terlibat dalam perubahan;

Harus sensitif terhadap outcomes proses pengembangan dan menciptakan kondisi yang kondisif bagi feedback yang dibutuhkan, kemudian menindak lanjutinya dengan melibatkan beberapa pihak dalam mendiskusikan ide-ide dan prakteknya (Duigan, P.A. and Macpherson, 1992, p. 84). 
Kompetensi adalah kemampuan melaksanakan sesuatu yang diperoleh melalui pendidikan dan/atau latihan. Dalam hal ini kompetensi mengacu kepada perbuatan dan kinerja di dalam pelaksanaan tugas-tugas kependidikan. Dengan melihat definisi diatas mengisyaratkan bahwa jabatan, seperti halnya kepala sekolah seharusnya memerlukan landasan dan sertifikasi melalui pendidikan profesional ataupun akademik.

Dari definisi-definisi di atas dapat diperoleh definisi kemampuan manajerial sekolah adalah kemampuan kepala sekolah dalam mengelola sumber daya yang ada dengan menjalankan fungsi-fungsi kepemimpinan untuk merespon tuntuan perubahan zaman dan tercapainya tujuan tujuan pendidikan yang telah ditetapkan secara efektif, efisien, dan produktif. Adapun indikatorindakator kemampuan manajerial kepala sekolah adalah (1) technical skill (kemampuan teknik), (2) human skill (kemampuan hubungan kemanusiaan), (3) conceptual skill (kemampuan konseptual), (4) akuntabilitas

\section{Komite Sekolah}

Komite sekolah merupakan wadah organisasi secara formal yang menampung partisipasi masyarakat dalam penyelenggaraan pembangunan pendidikan. Partisipasi dalam pengambilan keputusan akan meningkat, bila orang memahami maksud dan skopa suatu inovasi; sehingga mempertinggi efektivitas implementasinya (Stahl, 1972, p. 6-8). Membiasakan mengambil keputusan secara kolektif dengan kompetensi beraneka ragam akan membantu menciptakan situasi untuk meningkatkan partisipasi institusional.

Komite Sekolah berperan dan berfungsi sebagai (1) pemberi pertimbangan (advisory agency) dalam penentuan dan pelaksanaan kebijaksanaan pendidikan di satuan pendidikan, (2) pendukung (supporting agency) baik yang berwujud finansial, pemikiran maupun tenaga dalam penyelenggaraan pendidikan di satuan pendidikan, (3) pengontrolan (controlling agency) dalam rangka transparansi dan akuntabilitas penyelenggaran pendidikan dan keluaran pendidikan di satuan pendidikan, (4) mediator antara pemerintah (eksekutif) dengan masyarakat di satuan pendidikan (Depdiknas, 2002, p. 122). 
Merujuk dari beberapa definisi diatas dapat disimpulkan partisipasi masyarakat adalah keterlibatan masyarakat dalam rangka meningkatkan mutu, pemerataan, dan efisiensi pengelolaan pendidikan di satuan pendidikan sekolah. Adapun indikatorindikatornya adalah (1) partisipasi dalam pengambilan keputusan (advisory agency), (2) memberikan dukungan (supporting agency), (3) terlibat dalam kendali mutu (controlling agency), (4) sebagai mediator pemerintah dan masyarakat.

\section{Budaya Organisasi Sekolah}

Kultur (budaya) lebih berkaitan dengan aspek-aspek informal dari organisasi daripada elemen-elemen resminya yang selalu dilambangkan dengan struktur. Kebudayaan dapat dilihat dalam bentuk perilaku masyarakat, yang merupakan hasil dari pemikiran dan terrefleksikan dalam sikap dan tindakan. Tasmara menyatakan bahwa esensi budaya yaitu : (a) Budaya berkaitan erat dengan persepsi terhadap nilai dan lingkungan yang melahirkan makna dan pandangan hidup yang akan mempengaruhi sikap dan tingkah laku (the total way of life a people), (b) adanya pola nilai, sikap, tingkah laku (termasuk bahasa), hasil karya dan karsa, termasuk segala instrumennya, sistem kerja dan teknologi (a way thinking, feeling, and believing), (c) budaya merupakan hasil pengalaman hidup, kebiasaan-kebiasaan, serta proses seleksi (menerima atau menolak) norma-norma yang ada dalam cara dirinya berinteraksi sosial atau menempatkan dirinya di tengah-tengah lingkungan tertentu, (d) dalam proses budaya terdapat saling mempengaruhi dan saling ketergantungan (interdependensi), baik sosial maupun lingkungan nonsosial (Toto Tasmara, 2002, p. 161).

Kesimpulan dari berbagai macam pandangan tentang budaya atau kultur pada hakekatnya merupakan pandangan hidup (way of life) yang dapat berupa nilai-nilai, norma, kebiasaan, hasil karya, pengalaman, dan tradisi yang mengakar di suatu masyarakat dan mempengaruhi sikap dan perilaku setiap orang/masyarakat tersebut. Schein (Luthans, 1995) memberikan beberapa karakteristik yang merefleksikan aspek- aspek dalam budaya organisasi: (1). observed behavioral regularities, (2). Norms, (3). 
Dominant values, (4). Philosophy, (5). Rules, (6). Organization Climate (Ardini, 2006, p. 245).

Dari beberapa definisi diatas, maka definisi budaya organisasi sekolah merupakan pandangan hidup (way of life) yang dapat berupa nilai-nilai, norma, kebiasaan, hasil karya, pengalaman, dan tradisi yang mengakar di suatu masyarakat dan mempengaruhi sikap dan perilaku setiap orang/masyarakat dalam pengembangan strategik program pendidikan untuk perbaikan kualitas sekolah yang terus-menerus. Adapun indikator-indikatornya adalah (1) obeserved behavioral regularities; (2) norms; (3) dominant value. (4) philosophy; (5) rules dan (6) organization climate.

\section{Keefektifan Sekolah (School Effectiveness)}

Keefektifan merupakan ukuran pada suatu unit organisasi apakah mampu melaksanakan tugas-tugas manajerial yang dapat dilaksanakan dengan berhasil mencapai tujuan lembaga (Yukl, 1994, p. 5). Sedangkan menurut (Harold Koontz \& Heinz Weihrich, 1988, p. 8) Effectiveness is the achievement of objevtives. Artinya keefektifan diukur dengan tingkat keberhasilan dalam mencapai tujuan dengan kegiatan yang dilakukan.

Keefektifan adalah ukuran yang menyatakan sejauh mana sasaran/tujuan (kuantitas, kualitas, dan waktu) telah dicapai. Dalam bentuk persamaan, keefektifan adalah sama dengan hasil nyata dibagi hasil yang diharapkan. Sekolah efektif menunjukkan kesesuaian antara hasil yang dicapai dengan hasil yang diharapkan.

Berdasarkan uraian di atas dapat disimpulkan yang dimaksud dengan keefektifan sekolah adalah adanya kesesuaian antara tujuan-tujuan di pendidikan di sekolah dan hasil-hasil yang dicapai dengan standar nasional pendidikan yang terdiri dari: 1 ) standar isi; 2) standar proses; 3 ) standar kompetensi kelulusan; 4) standar pendidikan dan tenaga kependididkan; 5) standar sarana dan prasarana; 6) standar pengelolaan; 7) standar pembiayaan; 8) standar penilaian pendidikan.

Dalam pelaksanaanya, penelitian dilaksanakan dengan menyebarkan 400 (empat ratus) eksemplar kuesioner kepada 400 responden yang tersebar di lembaga pendidikan SMA Se- 
Wilayah Karesidenan Pati Jawa Tengah yang terdiri dari 100 SMA baik negeri maupun swasta dari 105 SMA yang ada. Berdasarkan hasil analisis data statistik deskriptif diperoleh jawaban responden mean pada indikator variabel penelitian baik variabel endogen maupun eksogen diperoleh angka sebesar 4,17 sampai 4,462 kecuali pada variabel budaya organisasi sekolah pada indikator B1 diperoleh mean sebesar 3, 887. Dengan demikian dapat dikatakan bahwa tingkat kemampuan manajerial kepala sekolah, komite sekolah, budaya organisasi sekolah, dan keefektifan sekolah pada SMA Se-Wilayah Eks Karesidenan Pati dapat dikatakan baik (61\%-80\%). Hal ini terlihat dari tingkatan yang paling rendah sampai yang tertinggi dari rating scale dan semantic differensial, dimana (Sangat Baik = 5 (81-100\%), Baik=4 (61-80\%), Cukup Baik=3 (41-60\%), Tidak Baik=2 (21-40\%), Sangat Tidak Baik=1 (0-20\%).

\section{Analisis Konfirmatory Faktor Model Pengukuran}

Model pengukuran konfirmatori factor variable digunakan untuk menguji kesesuaian model ( $f i t$ ) terhadap data yang digunakan dalam penelitian, yaitu variable laten variable endogen, dan variable exogen yaitu kemampuan manajerial kepala sekolah, komite sekolah, budaya organisasi sekolah dan keefektifan sekolah dapat dilihat sebagai berikut:

\section{a. Variabel Kemampuan Manajerial Kepala Sekolah}

Pengukuran konfirmatori variabel kemampuan manajerial kepala sekolah dengan 3 indikator dapat dilihat pada tabel 1 dibawah ini:

Tabel 1. Koefisien Regresi Variabel Kemampuan Manajerial Kepala Sekolah

\begin{tabular}{ccccc}
\hline Regression Weights & Estimate & SE & T-Value & P \\
\hline$M_{1} \leftarrow$ Kemampuan Manajerial Kepala Sekolah & 0,42 & 0,059 & 7,19 & 1,000 \\
\hline$M_{2} \leftarrow$ Kemampuan Manajerial Kepala Sekolah & 0,42 & 0,045 & 9,21 & 1,000 \\
\hline$M_{3} \leftarrow$ Kemampuan Manajerial Kepala Sekolah & 0,44 & 0,041 & 10,72 & 1,000 \\
\hline
\end{tabular}

Sumber: Data primer yang diolah

Tabel 1 di atas menunjukkan bahwa setiap dimensi pada variabel tersebut dinyatakan signifikan pada taraf $\alpha / 2(0,025)$, atau sama dengan $\pm 1,96$. Melalui perbandingan antara nilai $C R$ (critical ratio) dengan nilai $\mathrm{Z}$ tabel tersebut, ternyata untuk semua 
dimensi terbukti lebih besar dari nilai $\mathrm{Z}$ tabel, atau dilihat dari nilai probability (p) yang semua dimensi lebih besar dari 0,05 . Sehingga dapat disimpulkan bahwa koefisien factor loading yang dihasilkan untuk semua dimensi variabel Kemampuan Manajerial Kepala Sekolah dinyatakan signifikan.

\section{b. Variabel Komite Sekolah}

Pengukuran konfirmatori variabel Komite Sekolah dengan 4 indikator dapat dilihat pada tabel 2. dibawah ini :

Tabel 2. Koefisien Regresi Variabel Komite Sekolah

\begin{tabular}{l|c|c|c|c}
\hline Regression Weights & Estimate & SE & T-Value & $\mathrm{P}$ \\
\hline $\mathrm{K}_{1} \leftarrow$ Komite Sekolah & 0,41 & 0,036 & 11,31 & 0,05527 \\
\hline $\mathrm{K}_{2} \leftarrow$ Komite Sekolah & 0,46 & 0,036 & 12,74 & 0,05527 \\
\hline $\mathrm{K}_{3} \leftarrow$ Komite Sekolah & 0,50 & 0,039 & 12,97 & 0,05527 \\
\hline $\mathrm{K}_{4} \leftarrow$ Komite Sekolah & 0,49 & 0,039 & 12,64 & 0,05527 \\
\hline
\end{tabular}

\section{Sumber: Data primer yang diolah}

Tabel 2 di atas menunjukkan bahwa setiap dimensi pada variabel tersebut dinyatakan signifikan pada taraf $\alpha / 2(0,025)$, atau sama dengan $\pm 1,96$. Melalui perbandingan antara nilai CR (critical ratio) dengan nilai $\mathrm{Z}$ tabel tersebut, ternyata untuk semua dimensi terbukti lebih besar dari nilai $\mathrm{Z}$ tabel, atau dilihat dari nilai probability $(\mathrm{p})$ yang semua dimensi lebih besar dari 0,05. Sehingga dapat disimpulkan bahwa koefisien factor loading yang dihasilkan untuk semua dimensi pada variabel Komite Sekolah dinyatakan signifikan.

\section{c. Variabel Budaya Organisasi Sekolah}

Pengukuran konfirmatori variabel Budaya Organisasi Sekolah dengan empat indikator dapat dilihat pada tabel 3 dibawah ini :

Tabel 3. Koefisien Regresi Variabel Budaya Organisasi Sekolah

\begin{tabular}{lcccc}
\hline Regression Weights & Estimate & S.E. & T-Value & GFI \\
\hline $\mathrm{B}_{1} \leftarrow$ Budaya Organisasi Sekolah & 0,23 & 0,034 & 6,90 & 0,92 \\
\hline $\mathrm{B}_{2} \leftarrow$ Budaya Organisasi Sekolah & 0,28 & 0,028 & 10,17 & 0,92 \\
\hline $\mathrm{B}_{3} \leftarrow$ Budaya Organisasi Sekolah & 0,37 & 0,038 & 9,74 & 0,92 \\
\hline $\mathrm{B}_{4} \leftarrow$ Budaya Organisasi Sekolah & 0,36 & 0,032 & 11,16 & 0,92 \\
\hline $\mathrm{B}_{5} \leftarrow$ Budaya Organisasi Sekolah & 0,34 & 0,034 & 10,04 & 0,92 \\
\hline $\mathrm{B}_{6} \leftarrow$ Budaya Organisasi Sekolah & 0,35 & 0,035 & 10,08 & 0,92 \\
\hline
\end{tabular}

Sumber : Data primer yang diolah 
Tabel 3 di atas menunjukkan bahwa setiap dimensi pada variabel tersebut dinyatakan signifikan pada taraf $\alpha / 2(0,025)$, atau sama dengan $\pm 1,96$. Melalui perbandingan antara nilai $C R$ (critical ratio) dengan nilai $\mathrm{Z}$ tabel tersebut, ternyata untuk semua dimensi terbukti lebih besar dari nilai $\mathrm{Z}$ tabel, atau Goodness Fit Index (GFI) sebesar 0,92 lebih besar dari 0,90. Sehingga dapat disimpulkan bahwa koefisien factor loading yang dihasilkan untuk semua dimensi pada variabel Budaya Organisasi Sekolah dinyatakan signifikan.

\section{d. Variabel Keefektifan Sekolah}

Pengukuran Keefektifan Sekolah dengan delapam indikator dapat dilihat pemodelan fit.dapat dilihat pada tabel 4 dibawah ini:

Tabel 4. Koefisien Regresi Variabel Keefektifan Sekolah

\begin{tabular}{lcccc}
\hline \multicolumn{1}{c}{ Regression Weights } & Estimate & S.E. & T-Value & GFI \\
\hline $\mathrm{E}_{1} \leftarrow$ Keefektifan Sekolah & 0,36 & 0,031 & 11,50 & 0,98 \\
\hline $\mathrm{E}_{2} \leftarrow$ Keefektifan Sekolah & 0,33 & 0,029 & 11,27 & 0,98 \\
\hline $\mathrm{E}_{3} \leftarrow$ Keefektifan Sekolah & 0,32 & 0,030 & 10,87 & 0,98 \\
\hline $\mathrm{E}_{4} \leftarrow$ Keefektifan Sekolah & 0,34 & 0,024 & 13,91 & 0,98 \\
\hline $\mathrm{E}_{5} \leftarrow$ Keefektifan Sekolah & 0,26 & 0,036 & 7,10 & 0,98 \\
\hline $\mathrm{E}_{6} \leftarrow$ Keefektifan Sekolah & 0,25 & 0,032 & 7,78 & 0,98 \\
\hline $\mathrm{E}_{7} \leftarrow$ Keefektifan Sekolah & 0,26 & 0,030 & 8,57 & 0,98 \\
\hline $\mathrm{E}_{8} \leftarrow$ Keefektifan Sekolah & 0,29 & 0,036 & 7,91 & 0,98 \\
\hline
\end{tabular}

Tabel 4 di atas menunjukkan bahwa setiap dimensi pada variabel tersebut dinyatakan signifikan pada taraf $\alpha / 2(0,025)$, atau sama dengan $\pm 1,96$ Melalui perbandingan antara nilai $C R$ (critical ratio) dengan nilai $Z$ tabel tersebut, ternyata untuk semua dimensi terbukti lebih besar dari nilai $\mathrm{Z}$ tabel atau dilihat dari nilai Normed Fit Index (NFI) = 0.99, Comparative Fit Index (CFI) $=1$, Goodness of Fit Index (GFI) = 0.93 lebih besar dari 0,90. Sehingga dapat disimpulkan bahwa koefisien factor loading yang dihasilkan untuk 8 dimensi pada variabel Keefektifan Sekolah dinyatakan signifikan. 


\section{Analisis Struktural Equation Model (SEM)}

Visualisasi hipotesis dengan menggunakan diagram alur (path diagram) telah teruji dan dapat digambarkan dalam gambar 2 berikut ini :



Gambar 2 Struktural Equation Model (SEM) Model Akhir

Gambar 2 diatas menjelaskan bahwa model structural equation model (SEM) dinyatakan fit, hal ini dibuktikan dari kelayakan nilai-nilai uji seperti ditunjukkan dalam tabel 5 di bawah ini.

Tabel 5. Indeks Pengujian Kelayakan Structural Equation Modelling

\begin{tabular}{llccc}
\hline No & $\begin{array}{c}\text { Goodness of } \\
\text { fit index }\end{array}$ & $\begin{array}{c}\text { Cut of } \\
\text { Value }\end{array}$ & $\begin{array}{c}\text { Hasil } \\
\text { analisis }\end{array}$ & Evaluasi model \\
\hline 1 & CFI & $\geq 0,90$ & 0,94 & Baik \\
\hline 2 & NFI & $\leq 0,90$ & 0,92 & Baik \\
\hline
\end{tabular}

Sumber: data primer yang diolah (Lampiran 9)

Tabel 5 diatas menunjukkan, kelayakan model hipotesis yang telah dibangun dalam penelitian ini. Untuk mengetahui bahwa model hipotesis yang dibangun layak untuk digunakan dengan cara mambandingkan antara Cut-off Value dengan nilai dari hasil analisis SEM melalui program Lisrel. Uji hipotesis model menunjukkan bahwa model ini sesuai dengan data atau fit terhadap data yang digunakan dalam penelitian, seperti terlihat Normed Fit Index (NFI) $=0.92$, Comparative Fit Index (CFI) $=0.94$. 
Tabel 6. Koefisien Regresi Hasil Perhitungan Analisis SEM

\begin{tabular}{lcccc}
\hline \multicolumn{1}{c}{ Pengaruh } & Estimate & SE & T-Value & $\mathrm{R}^{2}$ \\
\hline $\mathrm{M}_{1} \leftarrow$ Kemam. Manajerial Kepala Sekolah & 0,45 & 0,057 & 7,76 & 0,51 \\
\hline $\mathrm{M}_{2} \leftarrow$ Kemam. Manajerial Kepala Sekolah & 0,43 & 0,043 & 10,00 & 0,74 \\
\hline $\mathrm{M}_{3} \leftarrow$ Kemam. Manajerial Kepala Sekolah & 0,41 & 0,041 & 10,24 & $\mathbf{0 , 7 6}$ \\
\hline $\mathrm{K}_{1} \leftarrow$ Komite Sekolah & 0,41 & 0,036 & 11,34 & 0,79 \\
\hline $\mathrm{K}_{2} \leftarrow$ Komite Sekolah & 0,46 & 0,036 & 12,74 & 0,91 \\
\hline $\mathrm{K}_{3} \leftarrow$ Komite Sekolah & 0,50 & 0,039 & 12,96 & $\mathbf{0 , 9 2}$ \\
\hline $\mathrm{K}_{4} \leftarrow$ Komite Sekolah & 0,49 & 0,039 & 12,65 & 0,90 \\
\hline $\mathrm{B}_{1} \leftarrow$ Budaya Organisasi Sekolah & 0,20 & - & - & 0,29 \\
\hline $\mathrm{B}_{2} \leftarrow$ Budaya Organisasi Sekolah & 0,26 & 0,047 & 5,63 & 0,63 \\
\hline $\mathrm{B}_{3} \leftarrow$ Budaya Organisasi Sekolah & 0,34 & 0,062 & 5,45 & 0,55 \\
\hline $\mathrm{B}_{4} \leftarrow$ Budaya Organisasi Sekolah & 0,33 & 0,048 & 6,85 & $\mathbf{0 , 6 7}$ \\
\hline $\mathrm{B}_{5} \leftarrow$ Budaya Organisasi Sekolah & 0,34 & 0,060 & 5,68 & 0,66 \\
\hline $\mathrm{B}_{6} \leftarrow$ Budaya Organisasi Sekolah & 0,35 & 0,062 & 5,56 & 0,61 \\
\hline $\mathrm{E}_{1} \leftarrow$ Keefektifan Sekolah & 0,36 & - & - & 0,82 \\
\hline $\mathrm{E}_{2} \leftarrow$ Keefektifan Sekolah & 0,32 & 0,022 & 14,47 & 0,80 \\
\hline $\mathrm{E}_{3} \leftarrow$ Keefektifan Sekolah & 0,32 & 0,023 & 13,64 & 0,77 \\
\hline $\mathrm{E}_{4} \leftarrow$ Keefektifan Sekolah & 0,34 & 0,017 & 20,30 & $\mathbf{0 , 9 9}$ \\
\hline $\mathrm{E}_{5} \leftarrow$ Keefektifan Sekolah & 0,27 & 0,032 & 8,28 & 0,45 \\
\hline $\mathrm{E}_{6} \leftarrow$ Keefektifan Sekolah & 0,26 & 0,029 & 8,86 & 0,49 \\
\hline $\mathrm{E}_{7} \leftarrow$ Keefektifan Sekolah & 0,26 & 0,026 & 9,81 & 0,56 \\
\hline $\mathrm{E}_{8} \leftarrow$ Keefektifan Sekolah & 0,29 & 0,033 & 8,88 & 0,49 \\
\hline
\end{tabular}

Sumber : Data primer yang diolah

Berdasarkan tabel 6 di atas dapat diuraikan sumbangan dari setiap indikator terhadap konstruk sebagai berikut : (1) Pengaruh yang paling besar yang membangun konstruk variabel Kemampuan Manajerial Kepala Sekolah adalah dimensi $\mathbf{M}_{3}$ (Technical skill), dengan nilai $\mathrm{R}^{2}$ sebesar 0,76. Artinya dimensi $\mathrm{M}_{3}$ (Technical skill) mampu menjelaskan sebesar $75 \%$ dan selebihnya 1 - 0,75 atau sebesar 0,24 atau 24\% yang diteliti dipengaruhi oleh variabel lain, (2) Pengaruh yang paling besar yang membangun variabel Komite Sekolah adalah dimensi $\mathrm{K}_{3}$ (Advisory Agency), dengan nilai $\mathrm{R}^{2}$ sebesar 0,92. Artinya dimensi $\mathrm{K}_{3}$ (Advisory Agency) mampu menjelaskan sebesar 0,92 dan selebihnya 10,92 atau sebesar 0,08 atau $8 \%$ yang diteliti dipengaruhi oleh variabel lain, (3) Pengaruh yang paling besar yang membangun konstruk variabel Budaya Organisasi Sekolah adalah dimensi $\mathrm{B}_{4}$ 
(Philosphy), dengan nilai estimasi sebesar 0,67. Artinya dimensi $\mathrm{B}_{4}$ (Philosphy), mampu menjelaskan sebesar 0,67 dan selebihnya 1- 0,67 atau sebesar 0,33 atau 33\% yang diteliti dipengaruhi oleh variabel lain, (4) Pengaruh yang paling besar yang membangun konstruk variabel Keefektifan Sekolah adalah dimensi $\mathrm{E}_{4}$ (Standar Tenaga Pendidik), dengan nilai estimasi sebesar 0.99. Artinya dimensi $\mathrm{E}_{4}$ (Standar Tenaga Pendidik), mampu menjelaskan sebesar 0,99 dan selebihnya $1-0,99$ atau sebesar 0,01 yang diteliti dipengaruhi oleh variabel lain.

\section{Pengujian Hipotesis}

Hasil ujian hipotesis penelitian dapat disimpulkan bahwa hipotesis yang menyatakan ada pengaruh yang signifikan antara variabel exogen terhadap variabel endogen. Atau dibuktikan melalui nilai probabilitas yang diperoleh yang menggambarkan probabilitas diterimanya hipotesis alternatif, dan sekaligus ditolaknya hipotesis nihil. Hasil analisis menghasilkan nilai CR lebih besar dari nilai tabel $\mathrm{Z} \pm 1,96$. Dengan demikian hipotesis dapat diterima, dan menolak hipotesis penerimaan Ho sekaligus penolakan Ho. Semua nilai CFI menunjukkan nilai lebih besar dari 0,90. Dengan demikian kesimpulan hipotesis seperti tabel 7.

Tabel 7. Kesimpulan Hipotesis

\begin{tabular}{|c|c|c|}
\hline No & Hipotesis & $\begin{array}{l}\text { Kesimpulan } \\
\text { Hasil } \\
\text { Pengujian }\end{array}$ \\
\hline 1 & $\begin{array}{l}\text { Keefektifan Sekolah ditentukan secara langsung oleh } \\
\text { Kemampuan Manajerial Kepala Sekolah di Sekolah Menengah } \\
\text { Atas (SMA) se-eks Karesidenan Pati }\end{array}$ & Ditolak \\
\hline 2 & $\begin{array}{l}\text { Budaya Organisasi Sekolah ditentukan secara langsung oleh } \\
\text { Kemampuan Manajerial Kepala Sekolah di Sekolah Menengah } \\
\text { Atas (SMA) se-eks Karesidenan Pati }\end{array}$ & Diterima \\
\hline 3 & $\begin{array}{l}\text { Keefektifan Sekolah ditentukan secara tidak langsung oleh } \\
\text { Kemampuan Manajerial Kepala Sekolah melalui Budaya } \\
\text { Organisasi Sekolah di Sekolah Menengah Atas (SMA) se-eks } \\
\text { Karesidenan Pati }\end{array}$ & Diterima \\
\hline 4 & $\begin{array}{l}\text { Keefektifan Sekolah tidak ditentukan secara langsung oleh } \\
\text { Komite Sekolah di Sekolah Menengah Atas (SMA) se-eks } \\
\text { Karesidenan Pati }\end{array}$ & Ditolak \\
\hline
\end{tabular}




\begin{tabular}{llc}
\hline No & \multicolumn{1}{c}{ Hipotesis } & $\begin{array}{c}\text { Kesimpulan } \\
\text { Hasil } \\
\text { Pengujian }\end{array}$ \\
\hline 5 & $\begin{array}{l}\text { Budaya Organisasi Sekolah tidak ditentukan secara langsung } \\
\text { oleh Komite Sekolah di Sekolah Menengah Atas (SMA) se-eks } \\
\text { Karesidenan Pati }\end{array}$ & Ditolak \\
\hline 6 & $\begin{array}{l}\text { Keefektifan Sekolah tidak ditentukan secara langsung oleh } \\
\text { Komite Sekolah melalui Budaya Organisasi Sekolah di Sekolah } \\
\end{array}$ & Ditolak \\
\hline 7 & $\begin{array}{l}\text { Keefengah Atas (SMA) se-eks Karesidenan Pati } \\
\text { Organisasi Sekolah di Sekolah Menengah Atas (SMA) se-eks }\end{array}$ & Diterima \\
& Karesidenan Pati & \\
\hline
\end{tabular}

Sumber : Data primer yang diolah

\section{Simpulan}

Model teoritis yang dibangun berdasarkan grand teori tentang Pengaruh Kemampuan Manajerial Kepala Sekolah dan Komite Sekolah Terhadap Budaya Organisasi Sekolah dan Dampaknya Pada Keefektifan Sekolah di Survey Pada Sekolah Menengah Atas (SMA) se-Wilayah Eks Karesidenan Pati Tahun didukung oleh data empiris. Hal ini terlihat dari hasil pengujian hipotesis pada model full Structural Equation Model (SEM) dinyatakan fit. Berdasarkan hasil analisis data besarnya pengaruh setiap variabel eksogen terhadap variabel endogen dan sumbangan indikator konstruk dapat dilihat sebagai berikut : (1). Keefektifan Sekolah tidak ditentukan oleh Kemampuan Manajerial Kepala Sekolah di Sekolah Menengah Atas (SMA) se-eks Karesidenan Pati, (2). Budaya Organisasi Sekolah ditentukan oleh Kemampuan Manajerial Kepala Sekolah di Sekolah Menengah Atas (SMA) seeks Karesidenan Pati, (2). Keefektifan Sekolah ditentukan secara langsung oleh Kemampuan Manajerial Kepala Sekolah ataupun tidak langsung melalui Budaya Organisasi Sekolah di Sekolah Menengah Atas (SMA) se-eks Karesidenan Pati, (3). Keefektifan Sekolah tidak ditentukan oleh Komite Sekolah di Sekolah Menengah Atas (SMA) se-eks Karesidenan Pati, (4). Budaya Organisasi Sekolah ditentukan oleh Komite Sekolah di Sekolah Menengah Atas (SMA) se-eks Karesidenan Pati, (5). Keefektifan Sekolah ditentukan secara langsung oleh Komite Sekolah ataupun tidak langsung melalui Budaya Organisasi Sekolah di Sekolah Menengah Atas (SMA) se- 
eks Karesidenan Pati, (6). Keefektifan Sekolah ditentukan secara langsung oleh Budaya Organisasi Sekolah di Sekolah Menengah Atas (SMA) se-eks Karesidenan Pati.

Adapun sumbangan dari setiap indikator terhadap konstruk diantaranya; a) Pengaruh yang paling besar yang membangun konstruk variabel Kemampuan Manajerial Kepala Sekolah adalah dimensi M3 (Technical Skill), dengan nilai dengan nilai R2 sebesar 0,76 atau 76\%, b) Pengaruh yang paling besar yang membangun variabel Komite Sekolah adalah dimensi K3 (Advisory Agency), dengan nilai $\mathrm{R}^{2}$ sebesar 0,92 atau 92\% Artinya dimensi K3 (Advisory Agency) mampu menjelaskan sebesar 0,92 dan selebihnya $1-0,92$ atau sebesar 0,08 atau $8 \%$ yang diteliti dipengaruhi oleh variabel lain, c) Pengaruh yang paling besgfar yang membangun konstruk variabel Budaya Organisasi Sekolah adalah dimensi $\mathrm{B}_{4}$ (Philosphy), dengan nilai estimasi sebesar 0,67. Artinya dimensi $\mathrm{B}_{4}$ (Philosphy), mampu menjelaskan sebesar 0,67 dan selebihnya $1-0,67$ atau sebesar 0,33 atau $33 \%$ yang diteliti dipengaruhi oleh variabel lain, d) Pengaruh yang paling besar yang membangun konstruk variabel Keefektifan Sekolah adalah dimensi $\mathrm{E}_{4}$ (Standar Tenaga Pendidik), dengan nilai estimasi sebesar 0.99. Artinya dimensi $E_{4}$ (Standar Tenaga Pendidik), mampu menjelaskan sebesar 0,99 dan selebihnya 1-0,99 atau sebesar 0,01 yang diteliti dipengaruhi oleh variabel lain. 


\section{DAFTAR PUSTAKA}

Ardini, L. (2006). Analisis Perbandingan Pengaruh Langsung Dan Tak Langsung Faktor Budaya Organisasi Dan Komitmen Terhadap Kinerja Karyawan Pada Uptd Parkir Kota Surabaya Lilis. Ekuitas.

Depdiknas. (2002). Manajemen Peningkatan Mutu Berbasis Sekolah; Buku 1 Konsep dan Pelaksanaan. (p. 2002). Jakarta: Direktorat SLTP Dirjen Dikdasmen.

Duigan, P.A. and Macpherson, R. J. S. (1992). Educative Leadership: A Practical Theory For New Administrators And Managers. (p. 84). London: Flamer Press.

Engkay, O. :, Guru, K., Subang, S., Trubus, J., \& Karang Anyar, K. (2010). Pengaruh Kemampuan Manajerial Kepala Sekolah Dan Faktor Yang Mempengaruhi Motivasi Kerja Terhadap Kinerja Guru Slb Di Kabupaten Subang. Jurnal Penelitian Pendidikan, 11(2). Retrieved from http://jurnal.upi.edu/ file/7-Engkay.pdf

Harold Koontz \& Heinz Weihrich. (1988). Management (p. 8). Singapore: McGraw-Hill International.

Stahl, R. L. J. (1972). Teacher Participation and Attitudes, Innovation Caharacteristic and the Adoption of Behavioral Objectives (p. 1972). The Florida State: University Microfilms International, Ann Arbor, Michigan.

Sugiyono. (2002). Statistika untuk Penelitian (p. 121). Bandung: CV. Alfa Beta.

Suharsimi Arikunto. (1990). Manajemen Penelitian. Jakarta: Rineka Cipta.

Tjalla, A. (2010). Potret Mutu Pendidikan Indonesia Ditinjau dari Hasil-Hail Studi Internasional. Seminar Nasional FKIP-UT, (3), 1-22. Retrieved from http://pustaka.ut.ac. id/pdfartikel/TIG601.pdf

Toto Tasmara. (2002). Etos Kerja Pribadi Muslim (p. 161). Jakarta: Raja Grafindo Persada. 
Ustama, D. D. (2009). Peranan Pendidikan Dalam Pengentasan Kemiskinan. Dialogue, 6(1), 1-12.

Wijanto, S. H. Structural Equation Model (2008). Yogyakarta: Graha Ilmu.

Yukl, G. (1994). Leadership in Organizations (Third Edit, p. 5). New Jersey: Prentice-Hall, Inc. 
